\title{
Let's evaluate the pandemic in terms of facts, not impressions
}

\begin{abstract}
Abbreviations: AP, acute pneumonia; COVID-19, coronavirus disease; SARS, severe acute respiratory syndrome; MERS, middle east respiratory syndrome
\end{abstract}

Our assessment of various events and phenomena depends, first of all, on our baggage of acquired knowledge, established stereotypes and worldviews. It is this kind of bias that affects the definition of our goals, decisions and specific actions, which often go against the observed facts and lose sight of important features of the object being studied.

The way experts perceive the current COVID-19 pandemic is one typical example of such a biased interpretation. The basis of the clinical picture of coronavirus infection is a lesion of the lung tissue, which, according to clinical and radiological and pathoanatomical data, is defined as viral inflammation and corresponds to the nosology "acute pneumonia" (AP).$^{1-4}$ According to the modern concept of AP, the only and main cause of this disease is considered to be its causative agent. This view of the nature of the AP is generally consistent with current events. Indeed, coronavirus infection causes inflammation of the lung tissue. At the same time, the usual treatment of AP with etiotropic drugs is unattainable in coronavirus infection due to the lack of such drugs.

These conditions are compounded by the continued spread of infection, despite strong and widespread anti-epidemic efforts, which creates a general sense of insecurity, anxiety and lack of any guarantees of a favorable outcome in the event of illness. However, the atmosphere of deep concern requires the search for optimal solutions, and a professional assessment of the situation should be based on facts and objective materials, and not on emotions and analogies. The materials accumulated during the pandemic period not only allow, but also oblige us to look at this phenomenon as a whole, as well as at the criteria for its assessment and interpretation, from the point of view of objective facts and figures.

At the time of this writing, the total number of people infected with the coronavirus in the world has exceeded 100 million, and their number continues to grow even during periods of total quarantine. The daily update of the growth of this indicator on special websites and in news programs and its literal perception quite logically has a psychological effect and creates social conflicts in society. For example, the administrative introduction of quarantine measures in connection with the spread of infection can be perceived as an infringement on personal freedom and serve as a basis for applying to the court. ${ }^{5}$ On the other hand, the authorities ' delay in introducing restrictive measures into everyday life is criticized for their shortsightedness. ${ }^{6}$

The latter circumstance deserves special attention, since the accusations against the leaders of the state were made by a group of medical experts who try to present purely medical problems as political. Such statements do not cause anything but regret, since no head of state in the world will be able to competently and effectively solve professional problems of medicine. In this case, an example is the results of the most stringent quarantines, for example, in the UK and Israel, which did not lead to a significant change in the situation.
Volume 8 Issue 2 - 202I

\author{
Igor Klepikov \\ Professor, Department of Pediatric surgery, retired, Russia
}

Correspondence: Igor Klepikov, Department of Pediatric surgery, retired, Russia, Tel + I-206-920-9643,

Emailigor.klepikov@yahoo.com

Received: February 28, 2021 | Published: May 12, 2021

In this regard, it should be noted that, first, the overall pandemic indicator reflects the total number of infected people, and not the number of cases.

Secondly, $80 \%$ of this number remain asymptomatic carriers of the coronavirus or have mild manifestations of the disease, and only $20 \%$ need hospitalization. ${ }^{2,7}$ This distribution among infected people suggests that the vast majority of us overcome such contact without any consequences and medical assistance.

Third, of course, the reduction in the number of infected people should lead to a reduction in the number of cases and the volume of hospitalizations, which has been repeatedly noted in different countries and regions during the current pandemic. However, the periods of such decline were temporary and did not have a drastic impact on the continuation of the pandemic and the severity of the disease. Therefore, anti-epidemic and quarantine measures can reduce the incidence of COVID-19 to some extent, but not solve this problem in general.

Fourth, the most severe cases of COVID-19, which account for approximately $5 \%$ of patients and require transfer to intensive care units, ${ }^{8,9}$ accumulate the main conceptual and therapeutic problems of the current pandemic. The fate of this group of patients today continues to depend on the system of views on the essence of pathology and treatment of AP, which has developed over the past decades under the didactic influence of antibiotics.

The causative agent of inflammation of the lung tissue continues to be considered as the main cause of the painful process and the main goal of treatment throughout the disease, although since the development of inflammatory transformation, it is the focus of inflammation in the lung that acts as the main diagnostic goal and is the main cause of severe functional disorders, isn't it? Before the onset of coronavirus infection, bacterial forms of AP had a diverse etiology and difficulties in determining it, so the huge range of clinical manifestations and treatment failures was always easily explained by the possible presence of various virulent microflora. But at the present time, nature makes it quite clear to us that such an interpretation is wrong. Under conditions of infection with a single pathogen, a huge variety of clinical variants continues to persist, which can no longer be explained by the difference in the virulence of one strain in different individuals. 
Fifth, the idea of causal relationships in the dynamics of the disease has not yet been reflected in the concept of AP, and the manifestations of the disease continue to be considered only as a result of the action of the pathogen. Therefore, the priority of suppressing the pathogen in the period when the severity of the patient's condition is determined by the volume of organ damage, and not by the etiology of the process, continues to dominate as the main direction of medical care. For example, a coronavirus can affect both $5 \%$ of lung tissue and 80 $90 \%$, but the severity of the process will be determined by the volume of inflammation, not its causative agent, right?

The didactic influence of the microbial theory of AP, formed as a result of a long-standing belief in the indispensability of antibiotics, continues to determine the priorities of therapeutic efforts today. Repeated attempts to use already known antiviral agents against coronavirus show the absence of any expected effect, ${ }^{8,10-13}$ and calls to continue testing already tested means instead of finding other ways to solve the problem only indicate the hypnotic influence of previous dogmas. ${ }^{14}$

The development of any pathological process has a certain sequence, so when the root cause is eliminated, the body needs time to eliminate the chain of its consequences. The body of patients with AP with its aggressive beginning in such situations simply does not have time to achieve the desired effect. In recent years, this phenomenon has been observed more often, even in conditions of successful antimicrobial therapy. The most significant example of this development is the so-called sterile empyema of the pleura.

Sixth, the underestimation of causal relationships in the pathogenesis of AP is accompanied by paradoxical efforts in diagnosis and treatment. Naturally, the root cause of circulatory disorders in this disease is localized in the small circle of blood circulation, where the main focus is located. The mechanisms of these disorders have long been known and described, as well as autonomous self-regulation and an inverse relationship between the two circulatory circles. At present, objective data have been obtained on violations of pulmonary blood flow at the level of the smallest vessels and in patients with coronavirus pneumonia, ${ }^{15}$ which once again confirms the commonality of the mechanisms of disease development, regardless of the etiology.

A widespread paradox is that the assessment of the condition of patients with AP is carried out on the basis of peripheral indicators, the value of which is inversely proportional to the pulmonary ones. If deviations of the systemic blood pressure are registered, which may be of an adaptive nature, they are corrected, since they continue to be considered (without confirmation) as a result of shock, now of viral origin. ${ }^{16}$ First of all, the commonality of the disease mechanisms and the equivalence of therapeutic efforts, rather than the nature of the pathogens of the process, determine the final results. In this regard, it is quite natural that the mortality rates from bacterial forms of AP $(30-50 \%)$ in recent years among patients in intensive care units ${ }^{17-21}$ are identical to this current indicator for COVID-19..$^{22-25}$

Seventh, the lack of a specific treatment for COVID-19 is the subject of extensive discussion and the search for solutions to this problem. In fact, we are talking about the treatment of viral pneumonia as the main threat of coronavirus infection, but the proposals for a new strategy to solve this problem are only a continuation of the previous concept of the AP. In fact, tactical solutions are proposed without revising the disease strategy, and the pathogen continues to be considered as the main factor not only in the development, but also in the dynamics of the process. ${ }^{8,26-31}$

Current trends in the study of the COVID-19 problem are focused on the cellular, molecular, and even genetic level of research, which involves the study of the mechanisms of coronavirus aggression and ways to eliminate them. ${ }^{1,26,27,31-34}$ Of course, the results of such studies are very necessary in order to prevent the intracellular penetration of viruses and reduce the frequency of diseases, but today the main question that requires the fastest possible answer is to effectively help the endless stream of already ill patients who are waiting for him now, today, and not tomorrow.

Currently, while medicine is busy searching for drugs to suppress the coronavirus, patients with COVID-19 continue to fill specialized hospital departments around the world, being the largest and heaviest contingent in them. Acute inflammation of the lung tissue remains the leading cause of severe illness and death. The concentration of such patients in the prescribed departments is an exorbitant psychological burden for their medical staff, who do not have ways to effectively suppress the pathological process. ${ }^{35-39}$

All this almost completely repeats the situation that the author of these lines went through 40 years ago. The concentration in one department of the most severe patients with AP differed only in that instead of coronavirus, staphylococcus was considered the leading pathogen and there was no such tense epidemiological situation as now. In general, the prospect of helping such patients seemed almost an unattainable goal, but a way out of this situation was still found. To do this, it was necessary to completely abandon the existing idea of the complete dependence of AP on its causative agent. It took a revision of views on the nature of the disease, but the results exceeded expectations. Today, these materials are published in 9 languages. ${ }^{40}$

At a time when antibiotics were unquestionably considered the basis of treatment and a panacea for many diseases, to declare them an auxiliary treatment for AP was a very responsible step. Today, the coronavirus pandemic has changed the conditions for choosing treatment exactly the opposite. The pointlessness of widespread use of antibiotics in this infection is known not only to medical professionals and it would be reasonable to expect a sharp restriction of this therapy. However, reality shows that, contrary to logic, the old treatment stereotypes remain widespread. Currently, up to $71-89,5 \%$ of patients with COVID-19 pneumonia receive antibiotics, despite the presence of co-infection only in some cases. ${ }^{41-44}$ In the UK, a new group of coronavirus patients is included in the treatment program for community-acquired pneumonia (1), and a number of experts insist on continuing the previous principles of empirical use of antibiotics in all patients. ${ }^{45}$

The latest information clearly demonstrates the difficulty of revising the usual stereotypes, even in the face of an obvious loss of their role and former significance. On the one hand, maintaining the authority of learned patterns continues to influence decision-making, despite the lack of necessary guidance, and on the other hand, the use of assistance tools that have lost their meaning in a new situation can be a reflection of despair as a result of the lack of an adequate replacement. To this should be added the increased role of viruses in the etiology of AP in recent years and long-standing concerns about the impact of long-term use of antibiotics on such dynamics. So far, this is only a postulate that is waiting for confirmation, but objective data on the transformation of the accompanying microflora that arose as a result of this type of therapy are one of the proofs of the changes that have already occurred. ${ }^{46,47}$

In the end, we must agree with the assessment of modern care for patients with COVID-19 pneumonia, which is given by I. ZaguryOrly and R.M. Schwartzstein, that "Physicians are treating patients, with unsparing generosity..." and the cause of therapeutic errors is "cognitive biases". ${ }^{48}$ Achieving the main goal that medicine sets 
today for the development of etiotropic agents for COVID-19 will not be able to completely solve the problem of those patients who have inflammation of the lung tissue. Antiviral drugs will not be able to have a rapid effect on the functional adaptation of the affected organ. During the period of increasing critical deviations, the direction of therapeutic efforts becomes crucial. To achieve the desired effect, especially in severe patients, pathogenetic methods are necessary, but for their targeted application, a radical revision of the concept of the disease should first be carried out and attention should be paid to the fact that AP is a circulatory, not a respiratory catastrophe.

\section{Conflicts of interest}

The author states that he has no conflict of interest.

\section{Funding}

This manuscript is a full initiative of the author and does not have any funding.

\section{Acknowledgments}

None.

\section{References}

1. Lipman M, Chambers RC, Singer M, et al. SARS-CoV-2 pandemic: clinical picture of COVID-19 and implications for research. Thorax 2020;75(8):614-616.

2. J. H. Stone, M. J. Frigault, N. J. Serling-Boyd et al. Efficacy of Tocilizumab in Patients Hospitalized with Covid-19.N ENGL J Med. 2020;383(24):2333-2344.

3. M. Ackermann, S. E. Verleden, M. Kuehnel at al. Pulmonary Vascular Endothelialitis, Thrombosis, and Angiogenesis in Covid-19. N Engl JMed. 2020;383(2):120-128.

4. Martines RB, Ritter JM, Matkovic E et al. COVID-19 Pathology Working Group (2020). Pathology and Pathogenesis of SARS-CoV-2 Associated with Fatal Coronavirus Disease, United States. Emerg Infect Dis. 2020 Sep;26(9):2005-2015.

5. Parmet WE. Roman Catholic Diocese of Brooklyn v. Cuomo - The Supreme Court and Pandemic Controls. N Engl J Med. 2021;384(3):199201.

6. Editorial from The New England Journal of Medicine. Dying in a Leadership Vacuum. N Engl J Med. 2020;383:1479-1480.

7. http://weekly.chinacdc.cn/fileCCDCW/journal/article/ccdcw/newcreate/ COVID-19.pdf

8. Zhou B, Kojim S, Kawamoto, et al. COVID-19 pathogenesis, prognostic factors, and treatment strategy: Urgent recommendations. J Med Virol. 2021;93(5):2694-2704

9. George PM, Barratt SL, Condliffe R, et al. Respiratory follow-up of patients with COVID-19 pneumonia. Thorax. 2020;75(11):1009-1016.

10. WHO solidarity trial consortium repurposed antiviral drugs for Covid-19 — interim WHO solidarity trial results. N Engl JMed. 2021;384(6)497511.

11. National Institutes of Health. NIH trial shows remdesivir accelerates recovery from advanced COVID-19. April 29, 2020.

12. Salama C, Han J, Yau L, et al. Tocilizumab in Patients Hospitalized with Covid-19 Pneumonia. N Engl J Med. 202;384(15):1473-1474.

13. Huang E, Jordan SC. Tocilizumab for Covid-19 - The Ongoing Search for Effective Therapies. N Engl J Med. 2020;383(24):2387-2388.

14. D. Rubin, K. Chan-Tack, J. Farley, et al. FDA Approval of Remdesivir A Step in the Right Direction. N Engl J Med. 2020;383(27):2598-2600.
15. Thillai M, Patvardhan C, Swietlik EM, et al. Functional respiratory imaging identifies redistribution of pulmonary blood flow in patients with COVID-19. Thorax. 2021;76:182-184.

16. Alhazzani W, Moller MH, Arabi YM, et al. Surviving sepsis campaign: Guidelines on the management of critically ill adults with coronavirus disease 2019 (COVID-19). Crit Care Med. 2020:46(5):854-887.

17. Liapikou A, Rosales-Mayor E, Torres A. The management of severe community acquired pneumonia in the ICU. June 2014, Expert Rev Respir Med. 2014;8(3):293-303.

18. Kim JW, Kim JJ, Yang HJ, et al. The Prognostic Factors of Pneumonia with Septic Shock in Patients Presenting to the Emergency Department. Korean Journal of Critical Care Medicine. 2015;30(4):258-264

19. Jason P, Dean NC, Guo Q, et al. Severe community-acquired pneumonia: timely management measures in the first 24 hours. Critical Care. 2016;20(1):237.

20. Vidal A, Santos L. Comorbidities impact on the prognosis of severe acute community-acquired pneumonia. Porto Biomedical Journal. 2017;2(6):265-272.

21. Ceccato A, Torres A. Sepsis and community-acquired pneumonia. Ann Res Hosp. 2018;2:7

22. Grasselli G, Zangrillo A, Zaneela A, et al. Baseline characteristics and outcomes of 1591 patients infected with SARS-CoV-2 admitted to ICUs of the Lombardy region, Italy. JAMA. 2020;323(16):1574-1581.

23. Richardson S, Hirsch JS, Narasimhan M, et al. Presenting Characteristics, Comorbidities, and Outcomes Among 5700 Patients Hospitalized With COVID-19 in the New York City Area. JAMA. 2020;323(20):2052-2059.

24. Renato Seligman and Beatriz Graeff Santos Seligman. Pandemic in the 21 st Century. The Challenge of COVID-19". EC Pulmonology and Respiratory Medicine. 2020;30-31.

25. Gupta S, Wang W, Hayek SS, et al. Association between early treatment with tocilizumab and mortality among critically ill patients with COVID-19. JAMA Intern Med. 2020;181(1):41-51.

26. El-Shimy IA, Mohamed MM, Hasan SS, et al. Targeting host cell proteases as a potential treatment strategy to limit the spread of SARS-CoV-2 in the respiratory tract. Pharmacol Res Perspect. 2021;9(1):e00698.

27. Mo Shehata. Covid-19; The Possible Medical Strategies. EC Pulmonology and Respiratory Medicine. 2020;03-07.

28. D. A. Berlin, R. M. Gulick, F. J. Martinez.Severe Covid-19. NEJM. 2020;383(25):2451-2460

29. Vats M, Mahaboub B, Mahmood W, et al. Second Wave of COVID-19 - Could it be More Lethal!!! - Novel 6 T's Strategies May Help. EC Pulmonology and Respiratory Medicine. 2020;17-21.

30. Schaye VE, Reich JE, Bosworth BP, et al. Collaborating Across Private, Public, Community, and Federal Hospital Systems: Lessons Learned from the Covid-19 Pandemic Response in NYC. NEJM Catalyst Innovations in Care Delivery. 2020;1(6).

31. Dzau VJ, Balatbat C. Strategy, coordinated implementation, and sustainable financing needed for COVID-19 innovations. The Lancet Journal. 2020;396(10261):1463-1534.

32. The Severe Covid-19 GWAS Group. Genomewide Association Study of Severe Covid-19 with Respiratory Failure. N Engl J Med. 2020;383:15221534 .

33. Cheepsattayakorn A, Cheepsattayakorn R. Pathogenesis and Pulmonary Pathology in SARS-CoV-2 (COVID-19) Host Cell Invasion". Acta Scientific Microbiology. 2020;5(1): 01-02.

34. Y. Wei, Huang H, Zhang R, et al.Association of Serum Mannose With Acute Respiratory Distress Syndrome Risk and Survival. JAMA Netw Open. 2021;4(1):e2034569. 
35. Lai J, Ma S, Wang Y, et al. Factors associated with mental health outcomes among health care workers exposed to coronavirus disease 2019. JAMA Netw Open. 2020;3(3):e203976-e203976.

36. Leiter RE. Reentry. NEJM. 2020;383:e141.

37. J. N. Rosenquist. The Stress of Bayesian Medicine - Uncomfortable Uncertainty in the Face of Covid-19. N Engl J Med. 2021;384:7-9.

38. Nioi M, Napoli PE, Lobina J, et al. COVID-19 and Italian Healthcare Workers From the Initial Sacrifice to the mRNA Vaccine: Pandemic Chrono-History, Epidemiological Data, Ethical Dilemmas, and Future Challenges. Front Public Health. 2021.

39. Chen X. Avoiding Defensive Medicine among Pandemic. EC Emergency Medicine and Critical Care 4.12.2020:49-53.

40. Klepikov I. Acute pneumonia. New doctrine and first treatment results.” LAP-Lambert Academic Publishing. 2020. ISBN-10:6202679174; ISBN-13: 9786202679176.

41. Rawson TM, Moore LSP, Zhu N, et al. Bacterial and fungal co-infection in individuals with coronavirus: A rapid review to support COVID-19 antimicrobial prescribing [published online ahead of print].Clin Infect Dis. 2020;71(9):2459-2468.
42. Beović M. Doušak J. Ferreira-Coimbra, et al. Antibiotic use in patients with COVID-19: a 'snapshot' Infectious Diseases International Research Initiative (ID-IRI) survey. Journal of Antimicrobial Chemotherapy. 2020;75(11):3386-3390.

43. Kim D, Quinn J, Pinsky B, et al. Rates of co-infection between SARSCoV-2 and other respiratory pathogens. JAMA. 2020;323:2085-2086.

44. Moisés OT, Esteban QM, Mauricio QA, et al. Characterization of Mortality by Covid-19 in a Health System in Central Mexico. EC Pulmonology and Respiratory Medicine. 2020;20-22.

45. Huttner BD, Catho G, Pano-Pardo JR, et al. COVID-19: don't neglect antimicrobial stewardship principles! Clinical Microbiology and Infection. 2020;26(7):808-810.

46. Jernigan JA, Hatfield KM, Wolford H, et al. Multidrug-Resistant Bacterial Infections in U.S. Hospitalized Patients, 2012-2017. $N$ Engl J Med. 2020;382:1309-1319.

47. Guggenbichler S, Fey T. Guggenbichler JP. Dramatic Increase of Multiresistant Microorganisms We are approaching the Postantibiotic Era? Integ Biomed Sci. 2019;5(1):74-83.

48. Zagury-Orly RM. Schwartzstein. Covid-19 - A Reminder to Reason. $N$ Engl J Med. 2020;383:e12 